\title{
An empirical study on measuring technical performance of industry based on ISIC classification
}

\author{
Arezo Khosravani and Younos Vakil Alroaia*
}

Department of Management, Semnan Branch, Islamic Azad University, Semnan, Iran, P.O.B: 35145-175

\begin{tabular}{l}
\hline A R T I C L E I N F O \\
\hline Article history: \\
Received March 2, 2012 \\
Received in Revised form \\
May, 1, 2012 \\
Accepted 29 April 2012 \\
Available online \\
May 10 2012 \\
\hline Keywords: \\
Technical efficiency \\
Stochastic frontier analysis \\
SFA \\
Efficiency
\end{tabular}

A B S T R A C T

\begin{abstract}
Measuring technical efficiency of different industries plays an important role on making managerial decisions. In this paper, we present an empirical study to measure technical efficiencies of various industries based on two-digit ISIC classification method in Iran. The proposed model uses stochastic frontier analysis (SFA) and implements maximum likelihood estimation (MLE) to estimate the parameters. The proposed study gathers the necessary data from year 2001 to year 2008 and implemented two methods where the second method is an extended model by using energy as part of efficiency estimation. The results of the survey indicate that auto industry was the most productive sector followed by equipments and the paper industry was among inefficient sectors.
\end{abstract}

(C) 2012 Growing Science Ltd. All rights reserved.

\section{Introduction}

Measuring technical efficiency of different industries plays an important role on making managerial decisions. It helps governmental agencies to set necessary rules and regulations and industry managers could find out more about possible difficulties, which exist within the industry. There are literally enormous efforts to contribute new methods and techniques for estimating technical efficiency. Ma et al. (2002) investigated the technical efficiency and Malmquist productivity indexes of a sample of 88 enterprises producing 72 percent of the industry's output for the period 1989-1997, with the aim of gaining some insights into the policy options. Cherchye and Van Puyenbroeck (2009) explained that a semi-radial efficiency measurement combines technical efficiency with a mix efficiency component. 
They proposed a semi-radial evaluation technique in two steps. In the first step, the proposed method builds on the price interpretation of the Koopmans efficiency notion to build some benchmarks and then the proposed model uses both a quantity-based distance measure and its dual equivalent to assess the mix efficiency factor. Chen et al. (2009) estimated stochastic frontier production functions to information of Chinese farms grouped into each of four regions - North, Northeast, East, and Southwest-from year 1995 to year 1999. These frontier production functions were demonstrated to have statistically various structures, and the elasticities provided some evidence of diminished marginal products of chemical inputs in the East and capital services in the North and Southwest. Labor had a low elasticity except in the North. They estimated the standardized technical efficiency scores for the farms and they were shown to have the same structure across regions and to be associated with the age of the household head, land fragmentation, and the village migration ratio, controlling for year impacts and village or regional fixed impacts.

Tingley et al. (2005) compared the results of stochastic production frontier (SPF) and DEA for segments of the English Channel fisheries. The impact of factors most influencing technical efficiency was analyzed using an SPF inefficiency model and tobit regression of DEA-derived scores. Such factors included vessel and skipper characteristics and it is argued that DEA can be used as an alternative to SPF techniques when there was difficulty in specifying the correct SPF model. The authors concluded that there was a general consistency between SPF and DEA analyses in regard to the factors affecting TE.

Gregg (2009) used two sets of nineteenth century farming information on Cherokee households to estimate Shephard output distance functions and to determine the Cherokee technical efficiency. Controlling for farm size, market orientation, spatial heterogeneity and experience, technical efficiency was between $7 \%$ and $9 \%$ greater in mixed-blooded households than in full-blooded households. Nevertheless, using pooled time series information of post-removal Cherokee farm households in North Carolina, Cherokee technical efficiency ranged from $0 \%$ to $4 \%$ less than the efficiency of their neighboring white farmers. Bozec and Dia (2007) analyzed the board-performance relationship for a group of 14 Canadian SOEs as a unique approach since SOEs do not have major control devices other than the board. As the interaction impact between the board and other corporate governance structures was expected to be low, there is normally no full control for the potential impact of different control devices. They used data envelopment analysis (DEA) to measure the performance of the SOEs. The results from the multivariate analysis recommended that board size and board independence were positively associated with firm technical efficiency only when SOEs were exposed to market discipline.

Chang and $\mathrm{Hu}$ (2010) introduced total-factor energy productivity change index (TFEPI) based on the concept of total-factor energy efficiency and the Luenberger productivity index to make an assessment the energy productivity change of regions in China with a total-factor framework. They explained that the TFEPI could be decomposed into change in energy efficiency and shift in the energy use technology. Their results indicated that China's energy productivity was decreasing by $1.4 \%$ per year during 2000-2004. The average total-factor energy efficiency improved about $0.6 \%$ per year, while total-factor energy technical change declined progressively $2 \%$ annually. The factors influencing TFEPI were also examined: (1) The east area had a higher TFEPI than the central and west area; (2) increasing the development status and electricity share of energy consumption would 
improve the region's TFEPI performance, while increasing the proportion of GDP generated by the secondary industry deteriorated TFEPI of a region.

Zhou et al. (2011) presented a time-variant estimation of technical efficiency in post-reform China and used a fully nonparametric stochastic model to measure technical efficiency. They reported that the average technical efficiency had declined in the mid-1980s but increased since 1992 and Eastern and Southern regions showed a higher than national average level of technical efficiency. Setiawan et al. (2012) studied the relationship between technical efficiency and industrial concentration in the Indonesian food and beverages sector. They obtained firm-level information from the Indonesian Bureau of Central Statistics (BPS) to estimate technical efficiency scores and calculate measures of industrial concentration. The results indicated that the food and beverages industry was characterized by high industrial concentration and firms in the industry were inefficient. The Granger-causality test recommended a one-way direction of causality, with industrial concentration having a negative influence on technical efficiency, at the sector level. They concluded that the quiet-life hypothesis, rather than the efficient-structure hypothesis, applies to the Indonesian food and beverages industry.

In this paper, we present an empirical study to measure technical efficiencies of different sectors of Iranian industries. There has been a law adapted from Unido to classify industry based on the proposed ISIC method and there are 23 main categories in this industry. This paper is organized as follows. We first present the methodology in section 2 and section 3 explains details of our findings. The paper concludes the contribution at the end to summarize the paper.

\section{Methodology}

Data of industrial workshops are considered as data panel for period of 2001-2008, which were gathered from the website of statistical centre of Iran and were divided based on ISIC classification. Statistical community contains all the firms, which were active in industry sector. In this research we investigated the whole statistical community and did not use sampling and statistical community of industry sector are divided in 23 two-digit codes. According to the investigation, the method used in this research is Stochastic Frontier Analysis (SFA) (Aigner et al., 1977) or function of time in which first production function of firm was estimated with maximum likelihood estimation (MLE) (Kumbhakar \& Lovell, 2000), then parameters were extracted and performance of each firm was compared with frontier production function and technical performance of each firm was estimated and calculated.

Then, adding energy variable to production function, the estimation was executed again and performance was calculated and these two methods were compared to each other. To estimate production function of 23-fold sections of industry and according to the investigations and tasks performed in the past, translog are used and dependent variables were level of production or added value of different codes in industry sector. Independent and effective variables contain level of labor force employed (L) and capital stock $(\mathrm{K})$ in different sectors of industries and amount of energy consumed in the industry sector in the second model. General form of production function is as follows:

$\ln Y=\beta_{\circ}+\frac{1}{2} \beta_{k} \sum_{i=1}^{n} X_{i} \sum_{j=1}^{m} X_{j} \quad k=12 \cdots \quad i=12 \cdots, n \quad j=12 \cdots, m$ 
where $Y$ represents the value added, $X_{i}$ and $X_{j}$ are labor force employed (L) and capital stock (K) in different sectors of industries and $\beta_{i}$ represents estimated parameters.

\subsection{Estimating maximum likelihood}

Maximum likelihood estimations method (Coelli et al., 2005) is used to estimate stochastic frontier production function of teranslog parameters assuming the existence of inefficiency. Note that energy also plays an important role in creating value added specially in some industries such as steel industry. Therefore, we need to add energy as part of our estimation. Let Qe be amount of energy used in different industries. Therefore we have,

$$
\begin{aligned}
& \ln Y=\beta_{\circ}+\beta_{1} \ln L+\beta_{2} \ln K+\beta_{3} \ln Q e+\frac{1}{2} \beta_{4}(\ln L)^{2}+\frac{1}{2} \beta_{5}(\ln K)^{2}+\frac{1}{2} \beta_{6}(\ln Q e)^{2}+\frac{1}{2} \beta_{7}(\ln L)(\ln K) \\
& +\frac{1}{2} \beta_{8}(\ln L)(\ln Q e)+\frac{1}{2} \beta_{9}(\ln K)(\ln Q e)
\end{aligned}
$$

where $\mathrm{Y}$ is the level of production, $\mathrm{L}$ is the number of labor force, $\mathrm{K}$ is the level of capital, Qe is the amount of energy consumed and $\beta 0$ to $\beta 9$ are function parameters.

\section{Empirical Result}

This section is associated with analyzing the results estimated from the model, where according to the article listed in previous sections, first production function parameters are estimated using maximum likelihood and the results are provided in a table, then technical performance and inefficiency of inputs is calculated and the averages are obtained. Table 1 shows details of our results.

\section{Table 1}

Estimating translog stochastic frontier production function parameters

\begin{tabular}{lllll}
\hline Parameters & Detail & Estimation & $\begin{array}{l}\text { Standard } \\
\text { deviation }\end{array}$ & Statistics t \\
\hline$\beta_{\circ} *$ & Width from the source & 7.53 & 1.85 & 4.07 \\
\hline$\beta_{1 *}$ & $=X_{1}$ number of labor force $(\ln$ & 1.29 & 0.38 & 3.35 \\
\hline$\beta_{2}$ & $\left.=X_{2}\right)$ level of capital(ln & -0.09 & 0.08 & -1.11 \\
\hline$\beta_{3 *}$ & $(1 / 2)\left(X_{1}\right)^{2}$ & -0.09 & 0.004 & -5.29 \\
\hline$\beta_{4} *$ & $(1 / 2)\left(X_{2}\right)^{2}$ & -0.02 & 0.004 & 3.16 \\
\hline$\beta_{5} *$ & $(1 / 2)\left(X_{1}\right)\left(X_{2}\right)$ & -0.06 & 0.01 & 74.32 \\
\hline Gamma & $\gamma=\sigma_{u}^{2} / \sigma_{s}^{2}$ & 0.96 & 0.01 & \\
\hline
\end{tabular}

In Table 1, the parameters specified with * are significant in level of 5 percent. As we can observe from the results of Table 1, the results of estimating production function in industry sector of the country indicate that all the parameters are significant in level of 5 per cent except parameter $\beta_{2}$ and the gamma calculated is 0.96 , which are significantly meaningful. This shows the validity of this method in estimating production function and the results are summarized as follows,

$\ln Y=7.53+1.29 \ln L-0 / 09 \ln K-0 / 45(\ln L)^{2}-0 / 01(\ln K)^{2}-0 / 03(\ln L)(\ln K)$ 
The results of our efficiency estimation in terms of different sectors are also calculated and they are classified in Table 2 .

\section{Table 2}

Performance of technical sectors of 23 -fold industry in terms of percentage

\begin{tabular}{llll}
\hline $\begin{array}{l}\text { Industry } \\
\text { code }\end{array}$ & Name of industry & $\begin{array}{l}\text { Technical } \\
\text { performance }\end{array}$ & $\begin{array}{l}\text { Lack of } \\
\text { efficiency }\end{array}$ \\
\hline 15 & Food and beverages industry & 26.57 & 73.43 \\
16 & Production of tobacco productions & 9.75 & 90.25 \\
17 & Textile production & 13.01 & 86.99 \\
18 & Production of clothes and setting color and so on & 3.59 & 96.41 \\
19 & Leather industry, making briefcase and so on & 5.68 & 94.32 \\
20 & Production of wood and wood products & 6.43 & 93.57 \\
21 & Production of paper and paper products & 11.16 & 88.84 \\
22 & Publish, print and distribution of medias & 7.44 & 92.56 \\
23 & Coke coal industry, refineries and so on & 91.76 & 8.24 \\
24 & Industries of chemicals & 72.60 & 27.40 \\
25 & Rubber and plastic products & 15.96 & 84.04 \\
26 & Non-metallic mineral Products industries & 29.70 & 70.30 \\
27 & Basic metals productions & 70.19 & 29.81 \\
28 & Fabric productions & 18.17 & 81.83 \\
29 & Producing classified machineries and equipments & 19.21 & 80.79 \\
30 & Producing office equipments, calculator, ... & 6.05 & 93.95 \\
\hline 31 & Producing generator and power transmission machineries ..... & 17.98 & 82.02 \\
\hline 32 & Producing radio, television and so on & 12.99 & 87.01 \\
\hline 33 & Producing medical and optical tools, and so on & 6.89 & 93.11 \\
\hline 34 & Producing vehicles, trailer and so on & 57.75 & 42.25 \\
\hline 35 & Producing other vehicles & 15.75 & 84.25 \\
\hline 36 & Producing furniture and unclassified textiles & 7.03 & 92.97 \\
\hline 37 & Recycling scrap metal and non-metal & 1.32 & 98.68 \\
\hline
\end{tabular}

According to the results obtained in the section, it can be concluded that industry sector of the country has a low average performance which means non-optimum using of production factors in this section. 22 per cent performance of the industry sector shows that this sector did not apply all of its capacities in using production factors and used production factors in a non-efficient manner. This caused the reduction of production function and also increase of cost function in this section, but has a more suitable situation in using resources, compared to the whole industry of the country, production industries of coal, refineries, chemical industries, production of main metals and finally car industry. In summary the industry represents an average of $77.09 \%$ of inefficiency and only $22.91 \%$ were efficient.

In this section, we present the results obtained from estimating production function of industry sector in which variable level of energy consumption was also added to production inputs. The results obtained from estimating production function of the whole industry is provided in Table 3 along with t-statistic for estimated coefficients. The gamma calculated is the validity of using Estimation of stochastic frontier function calculated after estimating production function by OLS. The gamma was calculated and its being significant was investigated. 
Table 3

Estimating translog stochastic frontier production function parameters by considering energy as production input

\begin{tabular}{lllll}
\hline parameters & Detail & Estimation & Standard deviation & t-Statistic \\
\hline$\beta_{\circ *}$ & Width from the source & -3.51 & 1.67 & -2.10 \\
$\beta_{1 *}$ & $X_{1}$ (Number of labor force) & 1.72 & 0.43 & 3.97 \\
$\beta_{2}$ & $X_{2}$ (level of capital) & -0.08 & 0.10 & -0.77 \\
$\beta_{3}$ & $X_{3}$ (energy consumption) & 0.60 & 0.44 & 1.34 \\
$\beta_{4 *}$ & $(1 / 2)\left(X_{1}\right)^{2}$ & 0.89 & 0.21 & 4.10 \\
$\beta_{5 *}$ & $(1 / 2)\left(X_{2}\right)^{2}$ & -0.02 & 0.006 & -3.28 \\
$\beta_{6 *}$ & $(1 / 2)\left(X_{3}\right)^{2}$ & 0.47 & 0.10 & 4.44 \\
$\beta_{7}$ & $(1 / 2)\left(X_{1}\right)\left(X_{2}\right)$ & 0.03 & 0.05 & 0.59 \\
$\beta_{8 *}$ & $(1 / 2)\left(X_{1}\right)\left(X_{3}\right)$ & -1.42 & 0.29 & -4.79 \\
$\beta_{9}$ & $(1 / 2)\left(X_{2}\right)\left(X_{3}\right)$ & -0.01 & 0.03 & 0.39 \\
Gamma & $\gamma=\sigma_{u}^{2} / \sigma_{s}^{2}$ & 0.97 & 0.008 & 112.56 \\
\hline
\end{tabular}

In Table 3, the parameters specified with $*$ are significant in level of 5 per cent. The results of estimating production function of industry sector of the country is that all the parameters are significant in level of 5 per cent, except parameters $\beta 2, \beta 3, \beta 7$ and $\beta 9$ and gamma calculated is 0.97 which finally the production function of the industry sector can be shown in Eq. (4) as follows,

$$
\begin{aligned}
\ln Y= & -3 / 51+1 / 72 \ln L-0 / 08 \ln K+0 / 60 \ln Q e+0 / 445(\ln L)^{2}-0 / 01(\ln K)^{2}+0 / 235(\ln Q e)^{2} \\
& +0 / 015(\ln L)(\ln K)-0 / 71(\ln L)(\ln Q e)-0 / 005(\ln K)(\ln Q e)
\end{aligned}
$$

\section{Table 4}

\begin{tabular}{|c|c|c|c|}
\hline Industry code & Name of industry & $\begin{array}{l}\text { Technical } \\
\text { performance }\end{array}$ & Inefficiency \\
\hline 15 & Food and beverages industry & 14.27 & 85.73 \\
\hline 16 & Production of tobacco productions & 53.77 & 46.23 \\
\hline 17 & Textile production & 9.96 & 90.04 \\
\hline 18 & Production of clothes and setting color and so on & 32.11 & 67.89 \\
\hline 19 & Leather industry, making briefcase and so on & 26.06 & 73.94 \\
\hline 20 & Production of wood and wood products & 11.08 & 88.92 \\
\hline 21 & Production of paper and paper products & 6.20 & 93.80 \\
\hline 22 & Publish, print and distribution of medias & 34.48 & 65.52 \\
\hline 23 & Coke coal industry, refineries and so on & 16.33 & 83.67 \\
\hline 24 & Industries of chemicals & 19.51 & 80.49 \\
\hline 25 & Rubber and plastic products & 14.59 & 85.41 \\
\hline 26 & Non-metallic mineral Products industries & 4.09 & 95.91 \\
\hline 27 & Basic metals productions & 3.24 & 96.76 \\
\hline 28 & Fabric metal productions & 28.06 & 71.94 \\
\hline 29 & Producing classified machineries and equipments & 31.20 & 68.89 \\
\hline 30 & Producing office equipments, calculator ... & 92.08 & 7.92 \\
\hline 31 & Producing generator and power transmission machineries and so on & 40.78 & 59.22 \\
\hline 32 & Producing radio, television and so on & 87.46 & 12.54 \\
\hline 33 & Producing medical and optical tools, and so on & 32.03 & 67.97 \\
\hline 34 & Producing vehicles, trailer and so on & 96.90 & 13.10 \\
\hline 35 & Producing other vehicles & 65.96 & 34.04 \\
\hline 36 & Producing furniture and unclassified textiles & 28.16 & 71.84 \\
\hline 37 & Recycling scrap metal and non-metal & 14.68 & 85.32 \\
\hline- & Whole industry & 32.74 & 67.26 \\
\hline
\end{tabular}

Technical performance of 23 -fold sectors of industry by considering energy level as production input 
As we can observe from the results of Table 4, auto industry was the most productive sector followed by equipments and the paper industry was among inefficient sectors. The other observation is that adding energy as an independent variable yields results that are more realistic and it helps better understand the behavior of industry. According to ISIC classification, basic metals sector is considered as one of the most inefficient industries. This could be due to cheap energy prices existed during the period of study.

\section{Conclusion}

In this paper, we have presented an empirical study to measure technical efficiencies of various industries based on two-digit ISIC classification method. The proposed model implemented SFA and implemented MLE to estimate the parameters. The proposed study gathered the necessary data from year 2001 to year 2008 and implemented two methods where the second method was an extended model by using energy as part of efficiency estimation. The results of the survey indicated that auto industry was the most productive sector followed by equipments and the paper industry was among inefficient sectors. According to the models estimated, it can be concluded that in general technical performance of industry sector is in a lower level, which indicate that the resources are not used, efficiently. In addition, adding energy level as an independent variable to the performance level model increased the efficiency of the whole industry to 10 percent, which shows the importance of this input in the industry sector, but still 32 per cent performance of the whole industry sector indicates lack of using production input optimally.

\section{Acknowledgement}

The authors would like to thank the anonymous referees for constructive comments on earlier version of this work.

\section{References}

Aigner, D.J., Lovell, C.A.K., \& Schmidt, P. (1977). Formulation and estimation of stochastic frontier production functions. Journal of Econometrics, 6, 21-37.

Bozec, R., \& Dia, M. (2007). Board structure and firm technical efficiency: Evidence from Canadian state-owned enterprises. European Journal of Operational Research, 177(3), 1734-1750.

Chang, T.P., \& Hu, J.L. (2010). Total-factor energy productivity growth, technical progress, and efficiency change: An empirical study of China. Applied Energy, 87(10), 3262-3270

Cherchye, L., \& Van Puyenbroeck, T. (2009). Semi-radial technical efficiency measurement. European Journal of Operational Research, 193(2), 616-625.

Chen, Z., Huffman, W.E., \& Rozelle, S. (2009). Farm technology and technical efficiency: Evidence from four regions in China. China Economic Review, 20(2), 153-161.

Coelli, T.J., Rao, D.S.P., O'Donnell, C.J., \& Battese, G.E. (2005). An Introduction to Efficiency and Productivity Analysis. $2^{\text {nd }}$ Ed. Springer, ISBN 978-0-387-24266-8.

Gregg, M.T. (2009).Technical efficiency estimates of Cherokee agriculture: A pre- and post-removal analysis. Journal of Socio-Economics, 38(5), 826-833.

Kumbhakar, S.C., \& Lovell, C.A.K. (2000). Stochastic Frontier analysis. Cambridge University Press, Cambridge.

Ma, J., Evans, D.G., Fuller, R.J., Stewart, D.F. (2002). Technical efficiency and productivity change of China's iron and steel industry. International Journal of Production Economics, 76(3), 293-312. 
1578

Setiawan, M., Emvalomatis, G., Oude Lansink, A. (2012). The relationship between technical efficiency and industrial concentration: Evidence from the Indonesian food and beverages industry. Journal of Asian Economics. To appear.

Tingley, D., Pascoe, S., \& Coglan, L. (2005). Factors affecting technical efficiency in fisheries: stochastic production frontier versus data envelopment analysis approaches. Fisheries Research, 73(3), 363-376

Zhou, X., Li, K.W., \& Li, Q. (2011). An analysis on technical efficiency in post-reform China. China Economic Review, 22(3), 357-372. 